\title{
Central haemodynamic changes after a meal
}

\author{
HENNING KELBEK, * OLE MUNCK, * NIELS J CHRISTENSEN, $\dagger$ \\ JOHN GODTFREDSEN $\ddagger$
}

From the *Department of Clinical Physiology and Nuclear Medicine, $\dagger$ Department of Internal Medicine and Endocrinology, and $\ddagger$ Department of Cardiology, Herlev Hospital, University of Copenhagen, Herlev, Denmark

SUMMARY Eight healthy people (seven men and one woman, aged 19 to 31 years) were studied by radionuclide cardiography when supine before and 30 minutes after a standard meal $(6300 \mathrm{~kJ}) \stackrel{P}{\longrightarrow}$ Control investigations were performed on a different day within a week of the standard meal. Theres was a median increase in cardiac output of $62 \%$ that was attributable to a $17 \%$ increase in heart rates and a $41 \%$ increase in stroke volume. Blood pressure and concentrations of plasma catecholamines did not change. The median end diastolic and end systolic volumes of the left ventricle increased by $41 \%$ so that the left ventricular ejection fraction was unchanged. There were no significant changes? during the control experiments.

In healthy people a meal caused an appreciable increase in stroke volume and dilatation of the lef ventricle. The activity of the sympathetic nervous system, as measured by plasma catecholamines did not change much, and changes in blood volume alone did not seem to explain the्ठ haemodynamic response to the meal.

Cardiovascular changes have been reported during eating and digestion. Experimental studies showed an early rise in cardiac output during eating, which was attributable to an increased heart rate; stroke volume fell. ${ }^{2}$ Most of the changes reverted to baseline values at the end of eating. ${ }^{2}$

There have been few human studies of the central haemodynamic changes after a meal, and the results of investigations in normal subjects are conflicting. ${ }^{34}$

We studied changes in left ventricular volume in healthy young people 30 minutes after a standard meal. We also measured plasma catecholamine concentrations.

\section{Patients and methods}

We studied eight healthy people (seven men and one woman; aged 19 to 31 years, median 26 years; median weight $74 \mathrm{~kg}$, range 63 to $94 \mathrm{~kg}$; and height of $1.80 \mathrm{~m}$, range 1.62 to $1.88 \mathrm{~m}$ ). The study protocol was approved by the local ethics committee.

STUDY PROTOCOL

The volunteers entered the laboratory about three

Requests for reprints to Dr Henning Kelbæk, Department of Clinical Physiology and Nuclear Medicine, Herlev Hospital, University of Copenhagen, DK-2730 Herlev, Denmark.

Accepted for publication 31 January 1989 hours after a light breakfast. They were examined after lying down for at least 15 minutes. Baselinen investigations were performed before the meal ando postprandial investigations $\mathbf{3 0}$ minutes after the end ${ }^{?}$ of the meal. Volunteers were randomly allocated tog have the standard meal or control investigation performed on the first day. Measurements for both studies were performed according to an identical procedure, except for the control study during which the volunteers moved freely for the period corresponding to ingestion of the meal.

STANDARD MEAL

The standard meal $(6300 \mathrm{~kJ})$ consisted of $280 \mathrm{~g}$ minced beef, $300 \mathrm{~g}$ potatoes, $50 \mathrm{~g}$ peas, $40 \mathrm{~g}$ sliced? cucumber, sauce, $150 \mathrm{~g}$ stewed apples with $30 \mathrm{~g}$ cream, and $400 \mathrm{~g}$ low-fat milk. It contained $22 \%$ ‥ protein, $35 \%$ carbohydrate, and $43 \%$ fat.

\section{INVESTIGATIONS}

Heart rate was monitored electrocardiographically and blood pressure was measured by sphygmomanometry. Blood samples were drawn from a을 cubital vein for the measurement of plasma adrenaline and noradrenaline by an isotope derivative assay. ${ }^{5}$ After in vitro labelling of autologous red blood cells with technetium- $99 \mathrm{~m}, \stackrel{\circ}{\mathrm{D}}$ cardiac output was measured by first passage radio- $\frac{?}{8}$ nuclide cardiography ${ }^{7}$ with injection of $500 \mathrm{MBq}$. $A \stackrel{\mathbb{}}{2}$ cardiac gamma camera equipped with an all purpose 
parallel hole collimator (Siemens) was positioned in the left anterior oblique projection over the heart to allow optimal separation of the left ventricular chamber. The camera was connected to a dedicated computer system (Scintiview, Siemens) and left ventricular ejection fraction was measured by the multigated equilibrium technique. ${ }^{8}$ Left ventricular end diastolic volume was calculated as the stroke volume (cardiac output divided by heart rate) divided by left ventricular ejection fraction, and left ventricular end systolic volume as the end diastolic volume minus stroke volume. Statistical analysis was performed using Pratt's rank test for paired data. A p value $<0.05$ was regarded as significant.

\section{Results}

Because the haemodynamic changes in the woman resembled those in the men, we pooled the results (table 1). After the meal cardiac output was increased by a median of $62 \%$ because of a $17 \%$ increase in heart rate $(p<0.01)$ and a $41 \%$ increase in stroke volume ( $p<0.01)$ (fig 1). Left ventricular end diastolic and end systolic volumes both increased by $41 \%(p<0.02)$, but there was no change in the left ventricular ejection fraction (fig 2). Blood pressure did not change significantly.

Neither plasma adrenaline nor plasma noradrenaline concentrations changed significantly after the meal (table 2).

In the control experiments there were no significant changes in plasma catecholamine concentration or in any haemodynamic variable (tables 1 and 2).

The distribution volume of labelled red blood cells showed an increase from a median of 5.201 (range
4.14 to $6 \cdot 14)$ to $5.611(4.46$ is 6.95$)$ after the meal $(p<0.05)$. The values in the control study were $5.521(4.15$ to 6.66$)$ and $5.531(3.94$ to 6.89$)$ respectively.
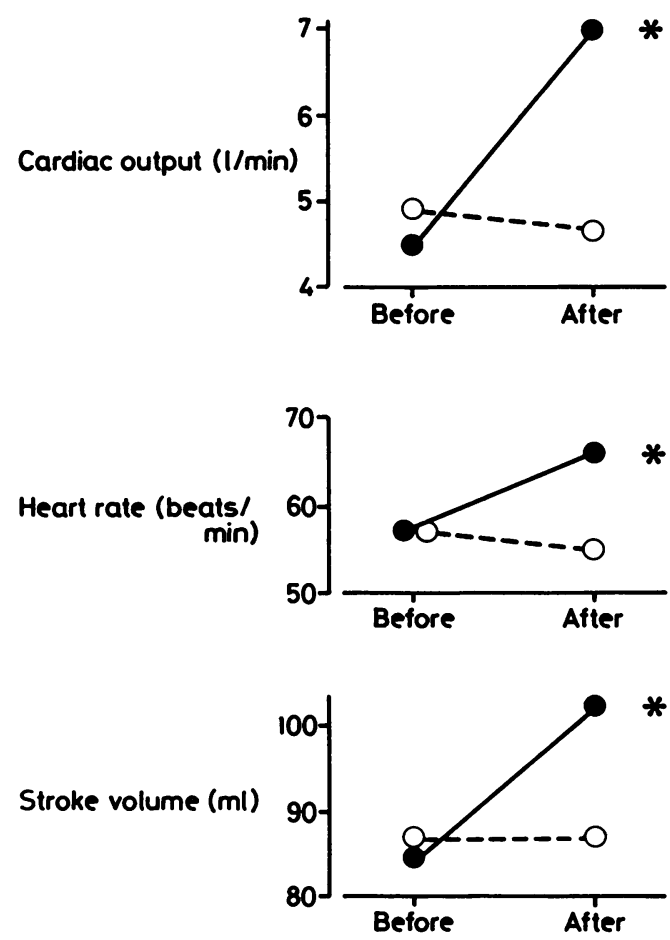

Fig 1 Haemodynamic variables before and after eating (closed circles). Open circles are values for the control experiments. Median values are shown. ${ }^{\star} p<0.01$.

Table 1 Haemodynamic data before $(B)$ and after $(A)$ ingestion of a standard meal and during a control study in eight healthy people (median (range))

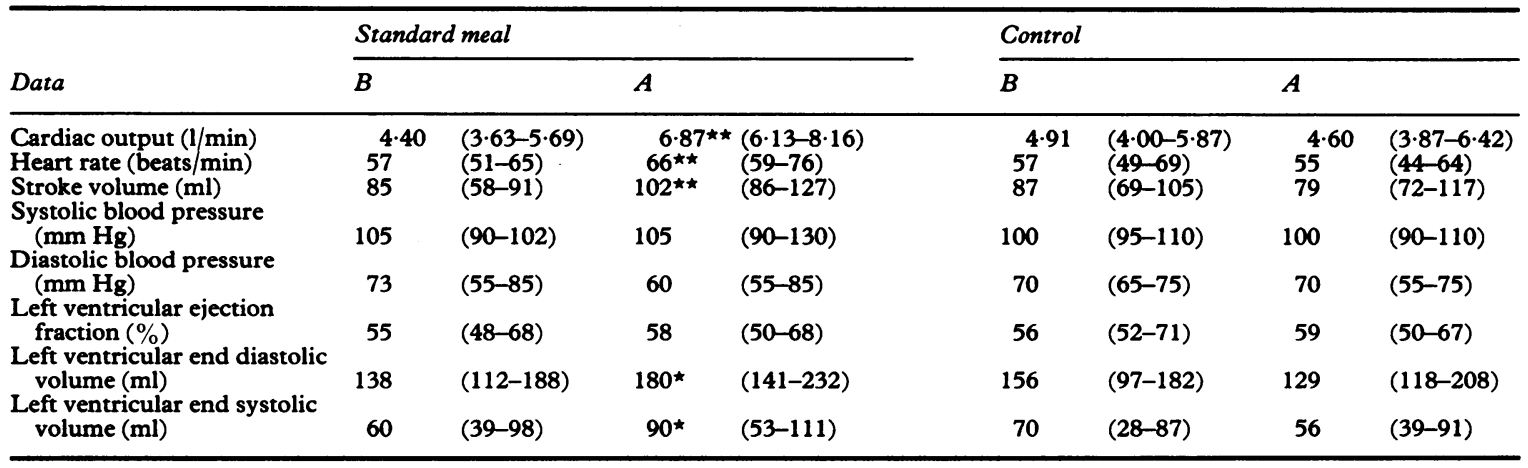

${ }^{\star} \mathrm{p}<0.02 ;{ }^{\star \star} \mathrm{p}<0.01$. 
$\operatorname{LVEF}(\%)$

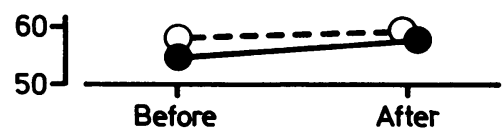

Fig 2 Left ventricular end diastolic volume (LVEDV), ejection fraction ( $L V E F$ ), and end systolic volume (LVESV) before and after food (closed circles). Open circles are values of the control experiments. Median values are shown. ${ }^{\star} p<0.02$.

\section{Discussion}

Knowledge of postprandial haemodynamic changes is almost entirely based on experimental studies in animals. In dogs feeding significantly increased cardiac output, heart rate, and arterial blood pressure. ${ }^{12}$ A rise in blood pressure was also seen in calves ${ }^{9}$ and pigs. ${ }^{10}$ Nevertheless, there are considerable species differences in the cardiovascular response to feeding. ${ }^{10}$ In most of these studies the haemodynamic changes were most prominent during feeding and most of the variables had reverted to baseline values at the end of feeding. So, the buccal phase of digestion may have had a considerable effect. ${ }^{1210}$

Previous studies in healthy people have shown no change in haemodynamic variables ${ }^{3}$ or postprandial increases in heart rate, blood pressure, and cardiac output. ${ }^{4}$ The discrepancy may be related to differences in size of the meals.

We studied haemodynamic variables in healthy people after a substantial Danish meal $(6300 \mathrm{~kJ}, 1500$ $\mathrm{kcal})$. The increase in cardiac output in all individuals after this meal was mostly attributable to an increase in stroke volume. This is at variance with animal studies in which stroke volume fell. Our results indicate that the increase in stroke volume was achieved by a considerable dilatation of the cardiac chambers. These findings are probably unique to primates. The increases in left ventricular end diastolic and end systolic volumes were of similar size, so that the left ventricular ejection fraction was unchanged. In contrast with the results of animal studies, ${ }^{11}$ Young et al found no significant change in plasma concentrations of catecholamines in healthy young people after ingestion of glucose, fat, or protein. ${ }^{12}$ Our results were similar. Thus neither the postprandial increase in heart rate nor the rise in stroke volume can be ascribed to an increased concentration of circulating catecholamines.

When cardiac output is measured by first pass radionuclide cardiography the distribution volume of the injected tracer is measured. This volume may be taken as an indicator of the blood volume and it increased slightly after the meal (by a median of $8 \%$ ). This rise alone can hardly explain the considerable increase in postprandial cardiac output that we found. In an earlier study the left ventricular ejection fraction increased after a meal in patients with congestive heart failure and moderately depressed values of left ventricular ejection fraction. ${ }^{13}$ In another study 10 patients with heart failure showed a postprandial increase in cardiac index..$^{14}$ However, spontaneous increases were also found in three out of five patients who were fasting. Such variation emphasises the need for controlled studies.

In our study lack of a change in mean arterial blood pressure and the considerable increase in cardiac output indicate a postprandial reduction in total peripheral resistance of at least $50 \%$. Fronek and Stahlgren reported a $33 \%$ increase in flow in the superior mesenteric artery during digestion in dogs. ${ }^{2}$ In addition, the increase in intestinal flow was confined to the mucosal and submucosal layers of the duodenum and jejunum 30 to 90 minutes after

Table 2 Plasma concentration of catecholamines in eight healthy people before (B) and after (A) a standard meal (medians (range))

\begin{tabular}{|c|c|c|c|c|c|c|c|c|}
\hline \multirow[b]{3}{*}{$\begin{array}{l}\text { Adrenaline }(\mathrm{ng} / \mathrm{ml}) \\
\text { Noradrenaline }(\mathrm{ng} / \mathrm{ml})\end{array}$} & \multicolumn{4}{|c|}{ Standard meal } & \multicolumn{4}{|c|}{ Control } \\
\hline & $B$ & & $A$ & & $B$ & & $A$ & \\
\hline & $\begin{array}{l}0.02 \\
0 \cdot 19\end{array}$ & $\begin{array}{l}(0.00-0.04) \\
(0.10-0.30)\end{array}$ & $\begin{array}{l}0.01 \\
0 \cdot 23\end{array}$ & $\begin{array}{l}(0.00-0.02) \\
(0.13-0.38)\end{array}$ & $\begin{array}{l}0.02 \\
0 \cdot 16\end{array}$ & $\begin{array}{l}(0.00-0.04) \\
(0 \cdot 12-0 \cdot 25)\end{array}$ & $\begin{array}{l}0.02 \\
0 \cdot 19\end{array}$ & $\begin{array}{l}(0.00-0.03) \\
(0 \cdot 11-0.32)\end{array}$ \\
\hline
\end{tabular}




\section{Central haemodynamic changes after a meal}

feeding and to the ileum at 90 minutes, whereas the blood flow to the colon was unchanged during this observation period. ${ }^{15-17}$ Thus the cardiovascular response to feeding seems to originate from the digestive organs and tissues. Vasoactive intestinal peptide may be important in these changes. ${ }^{18}$ In addition, the influence of the buccal phase of digestion on haemodynamic function remains to be settled.

The physiological implication of our findings is that much of the considerable increase in cardiac output after a meal is attributable to an increase in stroke volume. The increase in stroke volume is probably specific for primates and is achieved by a considerable dilatation of the ventricular chamber(s). Other investigations suggest that the central haemodynamic changes recorded after eating are secondary to changes in intestinal blood flow. Postprandial haemodynamic changes in patients with coronary disease should be studied.

This work was supported by the Danish Medical Research Council, the Danish Heart Foundation, and Novo's Foundation.

\section{References}

1 Ehrlich W, Tosheff J, Caldini P, Abbey H, Brady JV. Adaptation of cardiac output, coronary flow and other circulatory functions in dogs to exercise and to eating. Johns Hopkins Med J 1972;130:216-34.

2 Fronek K, Stahlgren LH. Systemic and regional hemodynamic changes during food intake and digestion in nonanesthetized dogs. Circ Res 1968;23: 687-92.

3 Jones WB, Thomas HD, Reeves TJ. Circulatory and ventilatory responses to postprandial exercise. $\mathrm{Am}$ Heart $J$ 1965;69:668-76.

4 Grollman A. Physiological variations in the cardiac output of man. Am J Physiol 1929;89:366-70.

5 Christensen NJ, Vestergaard P, Sørensen T, Rafaelsen OJ. Cerebrospinal fluid adrenaline and noradrenaline in depressed patients. Acta Psychiatr Scand 1980; 61:178-82.

6 Kelbæk H, Gjørup T, Fogh J. In vivo stability of in vitro labelled ${ }^{99 \mathrm{~m}} \mathrm{Tc}$-red blood cells for radionuclide determination of left ventricular ejection fractions and volumes. Nucl Med Commun 1986;7:541-7.

7 Kelbæk H, Hartling OJ, Skagen K, Munck O, Henriksen O, Godtfredsen J. First pass radionuclide determination of cardiac output: an improved gamma camera method. J Nucl Med 1987;28:1330-4.

8 Kelbæk H, Gjørup T, Brynjolf I, Christensen NJ, Godtfredsen J, Vestergaard B. Acute effects of alcohol on left ventricular function in healthy subjects at rest and during upright exercise. Am J Cardiol 1985;55: 164-7.

9 Bloom SR, Edwards AV, Hardy RN, Malinkowska K, Silver M. Cardiovascular and endocrine responses to feeding in the young calf. $J$ Physiol (Lond) 1975;253: 135-55.

10 Houpt KA, Baldwin BA, Houpt R, Hills F. Humoral and cardiovascular responses to feeding in pigs. $\mathrm{Am} \mathrm{J}$ Physiol 1983;244:R279-84.

11 Landsberg L, Young JB. Fasting, feeding and regulation of the sympathetic nervous system. $N$ Engl J Med 1978;298:1295-301.

12 Young JB, Rowe JW, Pallotta JA, Sparrow D, Landsberg L. Enhanced plasma norepinephrine response to upright posture and oral glucose administration in elderly human subjects. Metabolism 1980; 29:532-9.

13 Brown JM, White CJ, Sobol SM, Lull RJ. Increased left ventricular ejection fraction after a meal: potential source of error in performance of radionuclide angiography. Am J Cardiol 1983;51:1709-11.

14 Cornyn JW, Massie BM, Unverferth DV, Leier CV. Hemodynamic changes after meals and placebo treatment in chronic congestive heart failure. Am J Cardiol 1986;57:238-41.

15 Chou CC, Hsieh CP, Yu YM, et al. Localization of mesenteric hyperemia during digestion in dogs. $\mathrm{Am} \mathrm{J}$ Physiol 1976;230:583-9.

16 Gallavan RH, Chou CC, Kvietys P, Sit SP. Regional blood flow during digestion in the conscious dog. $\mathrm{Am}$ J Physiol 1980;238:H220-5.

17 Vatner SF, Patrick TA, Higgins CB, Franklin D. Regional circulatory adjustments to eating and digestion in the conscious unrestrained primate. $J A p p l$ Physiol 1974;36:524-9.

18 Frase LL, Gaffney FA, Lane LD, et al. Cardiovascular effects of vasoactive intestinal peptide in healthy subjects. Am J Cardiol 1987;60:1356-61. 